\title{
PRZEGLĄD METOD PLL DO SYNCHRONIZACJI Z SIECIĄ PRZEKSZTALTNIKÓW ENERGOELEKTRONICZNYCH
}

\author{
Piotr Lipnicki \\ Politechnika Lubelska, Wydział Elektrotechniki i Informatyki, Katedra Napędów i Maszyn Elektrycznych
}

Streszczenie. $W$ artykule przedstawiono metody synchronizacji przeksztaltników energoelektronicznych z siecia elektroenergetyczna oparte na pętli sprzężenia fazowego PLL. Przedstawione modele matematyczne oparte sq na transformacjach do wirujacego uktadu odniesienia. Modele symulacyjne wykonano w kilku wersjach: w zamkniętej pętli fazowej z synchronicznie wirujacym ukladem odniesienia PLL-SRF, w zmodyfikowanym ukladzie PLL-SRF $z$ uogólnionym integratorem drugiego rzędu SOGI oraz w podwójnie odprzężonym systemem z dwoma wirujacymi przeciwnie układami odniesienia DDSRF. Na podstawie wykonanych symulacji stwierdzono, że zamknięta pętla fazowa PPL z algorytmem SOGI pozwala uzyskać lepsza zbieżność, a algorytmy DDSRF poprawnie pracują nawet dla sieci niesymetrycznej z duża zawartościa harmonicznych czasowych.

Słowa kluczowe: pętla synchronizacji fazowej (PLL), algorytm SOGI, podwójne odprzężenie układu (DDSRF), synchronizacja sieci z napięciem odkształconym

\section{OVERVIEW OF METHODS FOR SYNCHRONIZING WITH THE POWER GIRD (PLL) FOR POWER CONVERTERS}

\begin{abstract}
This paper deals with crucial aspect of synchronizing power converters connected to the utility grid. Today, many components of Distributed Power Generation Systems (DPGS), such as Flexible Alternating Current Transmission Systems (FACTS), traction applications and power line conditioners containing power converters, have an important demand for optimized synchronization algorithms. It should be noted that also Transmission System Operator have specific requirements for synchronization with the grid. One of the possible ways to achieve a good performance in terms of synchronization is to use a Phase Locked Loop algorithm (PLL). This paper shows the results of investigation on different PLL methods, explaining how they work along with a summary describing their features, possibilities and drawbacks. In the end the impact of voltage unbalances and harmonics on synchronization algorithms is analyzed. The PLL methods were evaluate by the means of simulations.
\end{abstract}

Keywords: Phase-Locked Loop (PLL), harmonics, voltage unbalance, distribution systems, power converters, grid codes

\section{Wstęp}

Nowoczesna koncepcja sieci przesyłowych zakłada, że w przyszłości coraz większą rolę będą odgrywać Rozproszone Źródła Energii (RZE). Realizacja tej koncepcji wymaga współpracy wielu źródeł energii oraz możliwości dwukierunkowego przesyłu energii. Taką współpracę umożliwiają sprzęgi energoelektroniczne, które pozwalają m.in. na: zarządzanie energią w sposób efektywny, zapewniają wysoką jakość energii i ciągłość zasilania.

Wymagają one jednak podstawowych informacji o parametrach, w tym wartości częstotliwości i kąta fazowego sieci. Kąt ten, określany pomiędzy wektorem prądu i napięcia składowej podstawowej w punkcie przyłączenia układu przekształtnikowego do sieci, powinien być wykrywany ,online” w czasie rzeczywistym. Taka informacja jest nieodzowna do przeprowadzenia aktywnego sterowania przepływem energii czynnej jak i biernej między przekształtnikiem, a siecią.

Aby realizacja tych zadań była możliwa konieczna jest odpowiednia synchronizacja przyłączanego źródła z siecią. Dlatego też w każdym kraju operatorzy sieci posiadają odpowiednie regulacje prawne dotyczace synchronizacji. Polski operator PSE określa wyraźnie czas synchronizacji z siecią dla nowych jednostek, a także czasy re-synchronizacji urządzeń np. po zapadach napięcia, bądź chwilowych odłączeniach [8]. Od kilku lat w Europie stowarzyszenie operatorów sieci pracuje nad dokumentem określającym wspólne zasady i wymagania dotyczące przyłączonych źródeł energii. Ważnym aspektem jest możliwość szybkiej re-synchronizacji podczas krótkotrwałych zapadów napięcia [9], która pozwala utrzymać niewielkie źródła energii w stanie pracy bez konieczności uruchamiania długotrwałej procedury ich załączania. Odpowiednie algorytmy utrzymania synchronizacji są $\mathrm{w}$ stanie wykryć odpowiedni kąt, nawet w przypadku asymetrii napięcia, bądź też występowania harmonicznych.

Jedną z metod synchronizacji i identyfikacji kąta fazowego sieci jest zastosowanie algorytmów fazowej pętli zwrotnej - Phase Locked Loop (PLL). Dokładność synchronizacji ma bezpośredni wpływ na wydajność obwodów sterowania przekształtników [6]. Jednakże niepożądane zaburzenia takie jak asymetria napięcia, spadki napięcia, zapady napięcia, harmoniczne są szkodliwymi zjawiskami mającymi negatywny wpływ na działanie algorytmów PLL [6]. Aby zapewnić niezawodne działanie synchronizacji stosuje się różne metody uodparniające proces identyfikacji od zakłóceń sieci. Jedne skupiają się na dodaniu do urządzenia odpowiedniego filtra, układu kompensującego, inne natomiast proponują uwzględnienie tych zjawisk już w samej metodzie sterowania. W tym artykule zaprezentowany zostanie drugi typ rozwiązań.

\section{Teoria mocy chwilowej $w$ wirującym ukladzie odniesienia d-q [1]}

Nowoczesne algorytmy synchronizacji w dużej większości przypadków bazują na teorii mocy chwilowej d-q opracowanej przez Hirufumi Akagiego [1]. Teoria ta zaproponowała użycie tzw. układu odniesienia d-q-r, który wiruje synchronicznie $\mathrm{z}$ wektorem napięcia systemu trójfazowej sieci elektroenergetycznej. W układzie tym mierzone sygnały mają charakter stało-napięciowy/prądowy, co pozwala na zastosowanie dobrze znanych regulatorów PI. Ponadto moce chwilowe, (zarówno moc czynna jak i bierna) są zdefiniowane poprzez liniowo niezależne komponenty prądu $i_{\mathrm{d}} \mathrm{i} i_{\mathrm{q}}$. Aby przejść od układu trójfazowego do układu wirującego d-q należy wykonać szereg transformacji [1].

Pierwszym krokiem jest przejście z koordynat $a b c$ do $\alpha \beta$. Jest to realizowane w następujący sposób:

$$
\begin{gathered}
\overrightarrow{f_{a b c}}=\frac{2}{3} \cdot\left(f_{a} \cdot e^{j 0^{\circ}}+f_{b} \cdot e^{j 120^{o}}+f_{c} \cdot e^{-j 120^{o}}\right) \\
f_{\alpha}=\operatorname{Re}\left[f_{a b c}\right] \\
f_{\beta}=\operatorname{Im}\left[f_{a b c}\right] \\
\overrightarrow{f_{a b c}}=f_{\alpha}+j f_{\beta} ; f_{0}=\frac{1}{3}\left(f_{a}+f_{b}+f_{c}\right)
\end{gathered}
$$

gdzie: $f_{a}, f_{b}, f_{c}$ - to zmienne sygnału w fazie a, b i c, $f_{\alpha}, f_{\beta}, f_{0}$ - to zmienne sygnału w układzie stacjonarnym $\alpha \beta$. Przejście $\mathrm{z}$ układu $a b c$ do $\alpha \beta$ w postaci graficznej ilustruje rysunek 1 .



Rys. 1. Ilustracja przejścia z uktadu abc do $\alpha \beta$ za pomoca wektorów 
Transformacje te można również zapisać z zastosowaniem rzeczywistej macierzy transformacji dla przekształcenia prostego (5) i odwrotnego (6).

$$
\begin{gathered}
{\left[\begin{array}{l}
f_{\alpha} \\
f_{\beta} \\
f_{0}
\end{array}\right]=\frac{2}{3} \cdot\left[\begin{array}{ccc}
\cos 0 & \cos \frac{2 \pi}{3} & \cos \frac{2 \pi}{3} \\
\sin 0 & \sin \frac{2 \pi}{3} & -\sin \frac{2 \pi}{3} \\
\frac{1}{2} & \frac{1}{2} & \frac{1}{2}
\end{array}\right]\left[\begin{array}{l}
f_{a} \\
f_{b} \\
f_{c}
\end{array}\right]} \\
{\left[\begin{array}{l}
f_{\alpha} \\
f_{\beta} \\
f_{0}
\end{array}\right]=\frac{2}{3} \cdot\left[\begin{array}{ccc}
1 & -\frac{1}{2} & -\frac{1}{2} \\
0 & \frac{\sqrt{3}}{2} & -\frac{\sqrt{3}}{2} \\
\frac{1}{2} & \frac{1}{2} & \frac{1}{2}
\end{array}\right]\left[\begin{array}{l}
f_{a} \\
f_{b} \\
f_{c}
\end{array}\right]}
\end{gathered}
$$

Drugim etapem jest transformacja ze statycznego układu $\alpha \beta$ do wirującego układu $d q$. Realizowana jest ona w oparciu o informację o wartości chwilowej kąta:

$$
\begin{gathered}
f_{d}=\operatorname{Re}\left[f_{\alpha \beta} \cdot e^{-j \theta}\right]=\operatorname{Re}\left[f_{\alpha}+j f_{\beta}\right] \cdot e^{-j \theta}=\operatorname{Re}\left[\frac{f_{\alpha}+j f_{\beta}}{e^{j \theta}}\right] \\
f_{q}=\operatorname{Im}\left[\frac{f_{\alpha}+j f_{\beta}}{e^{j \theta}}\right] \\
\overrightarrow{f_{\alpha \beta}} \cdot e^{-j \theta}=\operatorname{Re}\left[f_{\alpha \beta}\right]+j \operatorname{Im}\left[f_{\alpha \beta}\right] \\
\overrightarrow{f_{\alpha \beta}} \cdot e^{-j \theta}=f_{d}+j f_{q} \\
{\left[\begin{array}{l}
f_{d} \\
f_{q} \\
f_{0}
\end{array}\right]=\left[\begin{array}{ccc}
\cos \theta & \sin \theta & 0 \\
-\sin \theta & \cos \theta & 0 \\
0 & 0 & 1
\end{array}\right]\left[\begin{array}{l}
f_{\alpha} \\
f_{\beta} \\
f_{0}
\end{array}\right]}
\end{gathered}
$$

gdzie: $f_{d}, f_{q}$ - to zmienne sygnału w układzie $d q, \theta$. Przejście $\mathrm{z}$ układu $\alpha \beta$ do $d q$ w postaci graficznej ilustruje rysunek 2 .

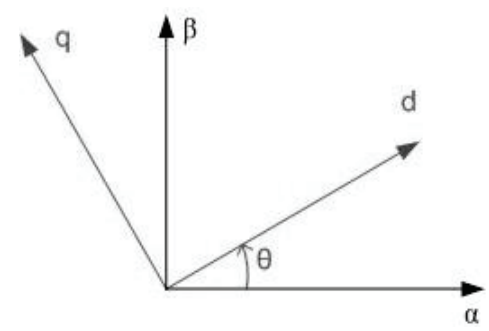

Rys. 2. Ilustracja przejścia z uktadu $\alpha \beta$ do dq za pomoca wektorów

\section{Modelowanie pętli PLL w wirującym układzie odniesienia}

Powszechnie stosowana metoda synchronizacji w systemie trójfazowym jest algorytm PLL w wirującym układzie odniesienia (PLL-SRF; Phase Locked Loop - Synchronous Reference Frame). W metodzie tej wartość chwilowa kąta fazowego jest wykrywana poprzez synchronizację wirującego układu odniesienia $\mathrm{z}$ wektorem napięcia sieci. Sygnał odniesienia jest synchronizowany $\mathrm{z}$ wektorem napięcia za pomocą regulatora proporcjonalno-całkującego.

Regulator ten dostraja oś $d$ wirującego układu odniesienia do wektora napięcia sieci. Można również dostroić oś $q$ wirującego układu odniesienia do wektora napięcia by otrzymać poprawnie działający mechanizm synchronizacji. Wybór pomiędzy tymi dwoma możliwościami zależy od aplikacji. W przypadku sterowania przekształtnikiem sieciowym preferowane jest dostrojenie osi $d$. W przypadku sterowania maszyną elektryczną powinno wybrać się oś $q$ [3].

Ogólną strukturę działania algorytmu PLL-SRF przedstawia rysunek 3 . Jak to zostało opisane wcześniej, metoda ta używa dwóch transformacji sygnałów ( $a b c$ do $\alpha \beta$ i $\alpha \beta$ do $d q$ ).

Układ z rys. 3 zawiera regulator PI i element całkujący. $\mathrm{W}$ celu synchronizacji z osią d używana jest tylko składowa $\mathrm{q}$. $\mathrm{Za}$ pomocą składowych napięcia $\mathrm{Vq} \mathrm{i} \mathrm{Vq*} \mathrm{(sygnał} \mathrm{odniesienia)}$ zostaje określony sygnał błędu, który jest podawany na wejście regulatora PI. Sygnał wyjściowy regulatora PI jest sumowany $\mathrm{z}$ wielkością $\omega \mathrm{ff}$, która reprezentuje pulsację składowej podstawowej $(\omega \mathrm{ff}=2 \pi 50)$. Po scałkowaniu sygnału pulsacji otrzymuje się wartość kąta $\theta$. Kąt ten jest wykorzystywany do dalszego przetwarzania sygnałów $\mathrm{w}$ różnych układach odniesienia.

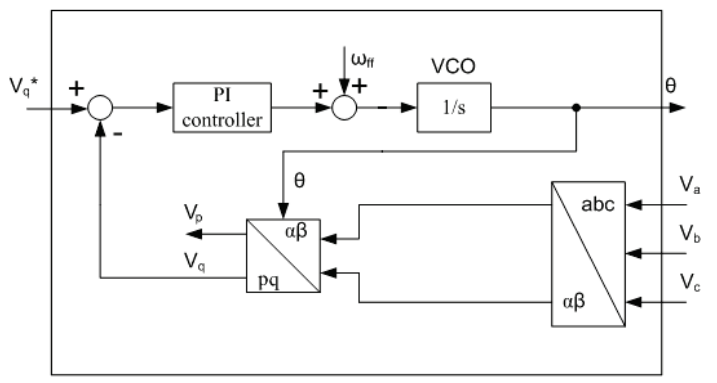

Rys. 3. Struktura blokowa algorytmu PLL-SRF, synchronizacja względem osi $q$

Aby uzyskać wymagane wysterowanie algorytmu PLL-SRF należy dobrać odpowiednie wzmocnienia dla regulatora PI w taki sposób, aby zminimalizować błąd uchybu synchronizowanej składowej. Metoda dostrajania nastaw regulatora, która jest opisana w [5], daje możliwość dokładnego określenia czasu regulacji i thumienia dla algorytmu PLL-SRF. W ten sposób łatwo można zaprojektować wolny, bądź szybki algorytm PLL dostrajając tylko dwa parametry. Metoda dostrojenia wymaga określenia transmitancji układu PLL przedstawionego na rys.3. Transmitancja projektowanego układu PLL ma postać [5]:

$$
H(s)=\frac{\mathrm{K}_{\mathrm{p}} \cdot s+\frac{\mathrm{K}_{\mathrm{p}}}{T_{i}}}{s^{2}+\mathrm{K}_{\mathrm{p}} \cdot s+\frac{\mathrm{K}_{\mathrm{p}}}{T_{i}}}
$$

gdzie: $K_{p}$ - wzmocnienie członu proporcjonalnego, $T_{i}-$ stała czasowa całkowania.

To wyrażenie można porównać $\mathrm{z}$ transmitancją drugiego rzędu, która ma postać:

$$
G(s)=\frac{2 \cdot \zeta \cdot \omega_{n} \cdot s+\omega_{n}^{2}}{s^{2}+2 \cdot \zeta \cdot \omega_{n} \cdot s+\omega_{n}^{2}}
$$

gdzie: $\omega_{n}$ - pulsacja naturalna, $\zeta$-współczynnik tłumienia.

Porównując równania (17) i (18) jesteśmy w stanie dobrać odpowiednie wzmocnienia dla regulatora PI w poniższy sposób. $\mathrm{Z}$ teorii sterowania [7] wiemy, że:

$$
T_{s}=\mathrm{k} \cdot \tau=\frac{k}{\zeta \cdot \omega_{n}} \Rightarrow \omega_{n}=\frac{k}{\zeta \cdot T_{s}}
$$

gdzie: $T_{s}$ - czas ustalania, $k$ - współczynnik tolerancji liczony jako logarytm naturalny, przy czym $\mathrm{k}=-\ln (\%$ tolerancji $)$.

Wybierając $k=4,6 \quad$ (co oznacza $10 \%$ dokładności) i współczynnik thumienia $\zeta=0,7$ z równań (17) i (18) otrzymamy wartość wzmocnienia członu proporcjonalnego regulatora PI:

$$
K_{p}=2 \cdot \zeta \cdot \omega_{n}=2 \cdot 0.7 \cdot \frac{4.6}{0.7 \cdot T_{s}}=\frac{9.2}{T_{s}}
$$

Posługując się dalej teorią sterowania mamy [7]:

$$
K_{i}=\frac{K_{p}}{T_{i}}=\omega_{n}^{2}
$$

gdzie: $K_{p}-$ wzmocnienie członu proporcjonalnego, $K_{i}$ - wzmocnienie członu PI, $T_{i}$ - stała czasowa całkowania.

$\mathrm{Z}$ powyższego wyrażenia i z poprzednich równań możemy wyliczyć stałą czasową sygnału wyjściowego członu całkującego w następujący sposób:

$$
T_{i}=\frac{K_{p}}{\omega_{n}^{2}}=\frac{2 \cdot \zeta \cdot \omega_{n}}{\omega_{n}^{2}}=\frac{2 \cdot \zeta}{\frac{4.6}{\zeta \cdot T_{s}}}=\frac{\zeta^{2} \cdot T_{s}}{2.3}
$$

Mając już dostrojony regulator PI można w pełni wykorzystać algorytm PLL. Wyniki symulacyjne działającego algorytmu przedstawia rys. 4 . 


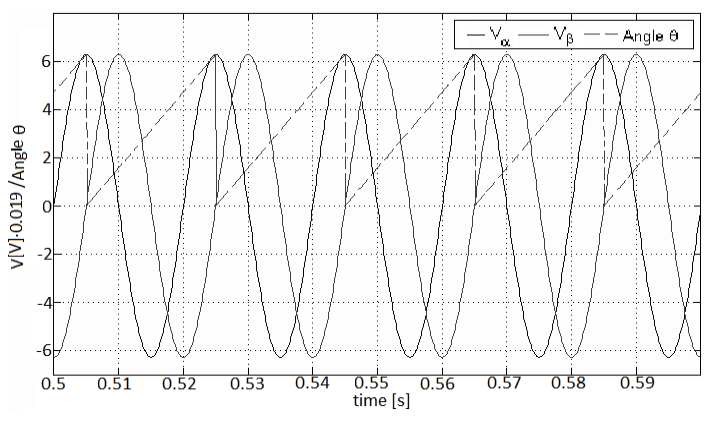

Rys. 4. Estymowany kąt napięcia sieci $\theta$ w przypadku symetrycznej sieci

Algorytm ten świetnie się sprawuje w przypadku, gdy nie występują zakłócenia i w sieci występuje symetria napięć. W przypadku jakichkolwiek zakłóceń, bądź niesymetrii napięć nie działa on poprawnie. Ilustruje to rys. 5 .

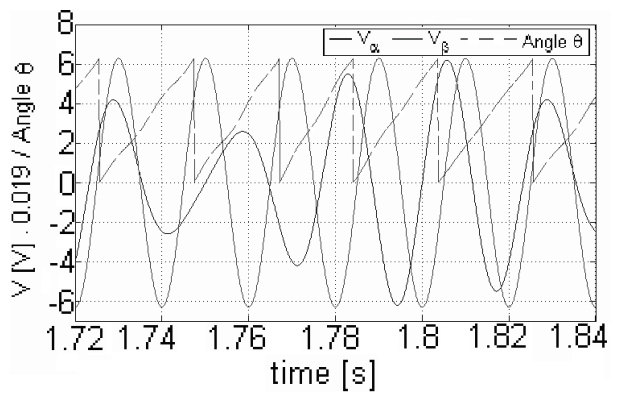

Rys. 5. Estymowany ką napięcia sieci $\theta$ w przypadku niesymetrycznej sieci wraz z napięciem sieci $w$ uktadzie stacjonarnym

\section{PLL w wirującym układzie odniesienia z mechanizmem SOGI}

Jednym z mechanizmów służących do synchronizacji może być zastosowanie dodatkowych układów całkujących SOGI (Second Order Generalized Integrator - Uogólniony układ całkujący drugiego rzędu) [6]. Strukturę działania algorytmu PLL-SRF zawierającą elementy SOGI prezentuje rys. 6.

Jak przedstawiono na schemacie sygnał pulsacji naturalnej wykrytej przez algorytm PLL jest wysyłany w pętli sprzężenia zwrotnego do dwóch elementów całkujących SOGI. Elementy te zapewniają dobrą filtrację sygnału. Skalę filtracji można dostroić za pomocą wzmocnienia elementów całkujących $\mathrm{K}_{\text {SOGI }}$. Należy zauważyć, że dynamika algorytmu synchronizującego jest silnie powiązana z przepustowością układu SOGI.

Dostrajając filtr SOGI trzeba brać pod uwagę warunki, w których algorytm PLL będzie stosowany, czy powinien być to algorytm szybki, czy wolniejszy, ale za to w większym stopniu odporny na zakłócenia i asymetrie napięć. Strukturę elementu SOGI przedstawia rys. 7.

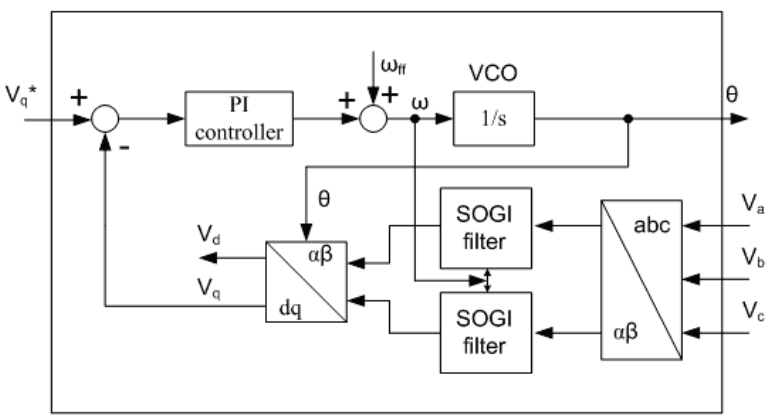

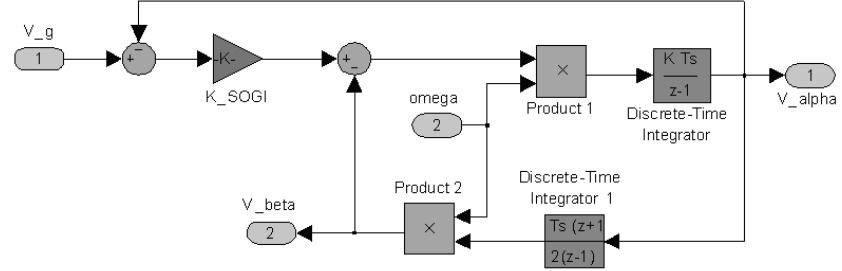

Rys. 7. Struktura SOGI

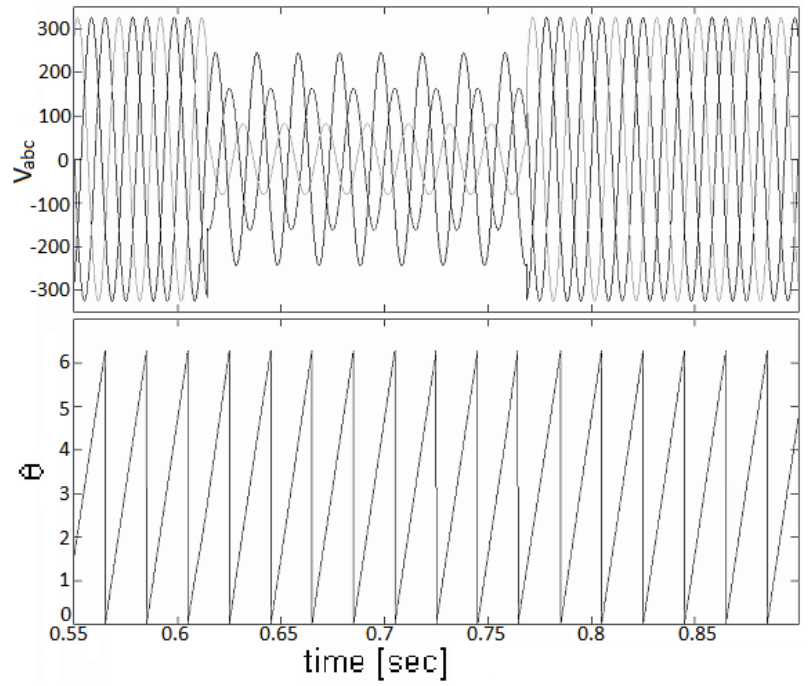

Rys. 8. Dziatanie PLL-SRF z SOGI

Działanie tego algorytmu w warunkach niesymetrii napięć ilustruje rys. 8.

Jak widać na rysunku 8, algorytm SOGI radzi sobie doskonale - nawet w przypadku asymetrii napięć. Można śmiało stwierdzić, że w rzeczywistych układach stosowanie algorytmu odpornego na zakłócenia i wyższe harmoniczne może być zalecane.

\section{PLL w podwójnie odsprzężonym synchronicznym układzie odniesienia DDSRF}

Algorytm synchronizacji z siecią w podwójnie odsprzężonym synchronicznym układzie odniesienia (DDSRF - Double Decoupled Synchronous Reference Frame) został zaproponowany $\mathrm{w}$ [7]. Korzysta on $\mathrm{z}$ transformacji sygnałów napięcia $\mathrm{z}$ układu $V_{a b c}$ do $V_{\alpha \beta}$ i z $V_{\alpha \beta}$ do $V_{d q}$. Metoda ta dąży do wykorzystania składowej zgodnej sygnału. Dzięki temu możliwe jest określenie fazowego kąta sieci $\theta$ nawet przy niesprzyjających warunkach tj. np. harmonicznych, czy też asymetrii napięcia. Ogólny schemat działania PLL-DDSRF przedstawia rys. 9.



Rys. 10. Algorytm PLL-DDSRF- osobne wirujace uklady odniesienia dla sktadowych wirujacych zgodnie i sktadowych wirujacych przeciwnie 
Ważnym elementem tej metody jest otrzymanie amplitudy napięcia i kąta fazowego w sposób szybki i dokładny. Realizowane jest to $\mathrm{w}$ następujący sposób. Wielkościami wejściowymi algorytmu są wyniki pomiaru napięć, które po transformacjach do układów $\alpha \beta$ kolejności zgodnej i przeciwnej określaja składowe zgodne i przeciwne w stacjonarnych układach odniesienia. Wektory te zostają określone w dwóch wirującym układach. Układ $d q^{+}$z kątem $\theta$ wiruje w kierunku zgodnym, a układ $d q-\mathrm{z}$ kątem $-\theta$ wiruje w kierunku przeciwnym. Wektor napięcia w układzie DDSRF może zostać przedstawiony jako [2]:

$$
\begin{aligned}
& \mathrm{v}_{\mathrm{dq}}^{+1}=V_{S}^{+1}\left[\begin{array}{l}
\cos (\omega t-\theta) \\
\sin (\omega t-\theta)
\end{array}\right]+V_{S}^{-1}\left[\begin{array}{c}
\cos \left(-\omega t+\phi^{-1}-\theta\right) \\
\sin \left(-\omega t+\phi^{-1}-\theta\right)
\end{array}\right] \\
& \mathrm{v}_{\mathrm{dq}}^{-1}=V_{S}^{+1}\left[\begin{array}{l}
\cos (\omega t+\theta) \\
\sin (\omega t+\theta)
\end{array}\right]+V_{S}^{-1}\left[\begin{array}{l}
\cos \left(-\omega t+\phi^{-1}+\theta\right) \\
\sin \left(-\omega t+\phi^{-1}+\theta\right)
\end{array}\right]
\end{aligned}
$$

gdzie $\mathrm{v}_{\mathrm{dq}}^{+1}, V_{S}^{+1}$ - to składowe zgodne, $\mathrm{v}_{\mathrm{dq}}^{-1}, V_{S}^{-1}$ - to składowe negatywne. Przyjmując następujące założenia [2]:

$$
\begin{aligned}
& \sin (\omega \mathrm{t}-\theta) \approx \omega \mathrm{t}-\theta, \cos (\omega \mathrm{t}-\theta) \approx 1-\frac{(\omega t-\theta)^{2}}{2}, \\
& -\omega t-\theta \approx-2 \omega t
\end{aligned}
$$

możemy równania (21) i (22) zapisać w następującej postaci:

$$
\begin{gathered}
\mathrm{v}_{\mathrm{dq}}^{+1}=V_{S}^{+1}\left[\begin{array}{c}
1-\frac{(\omega t-\theta)^{2}}{2} \\
\omega \mathrm{t}-\theta
\end{array}\right]+V_{S}^{-1}\left[\begin{array}{l}
\cos \left(-2 \omega t+\phi^{-1}\right) \\
\sin \left(-2 \omega t+\phi^{-1}\right)
\end{array}\right] \\
\mathrm{v}_{\mathrm{dq}}^{-1}=V_{S}^{+1}\left[\begin{array}{c}
\cos (2 \omega t) \\
\sin (2 \omega t)
\end{array}\right]+V_{S}^{-1}\left[\begin{array}{c}
\cos \left(\phi^{-1}\right) \\
\sin \left(\phi^{-1}\right)
\end{array}\right]
\end{gathered}
$$

Wartości stałe w (24) i (25) są tożsame z amplitudą $V_{S}^{+1}$ i $V_{S}^{-1}$ natomiast oscylacje $\mathrm{z}$ członem $2 \omega$ pojawiają się $\mathrm{W}$ skutek sprzężenia pomiędzy układami odniesienia wirującymi w przeciwnych kierunkach. Człony te można traktować jako perturbacje przy wykrywaniu amplitud sygnałów. Oddzielenie tych sygnałów odbywa się za pomocą specjalnych przekształceń, które zostały przedstawione na rys. 11 .

Jak widać na rysunku 11, zastosowanie prostych matematycznych przekształceń sygnałów pozwala na dokładne określenie amplitud i kąta fazowego sygnałów napięcia sieci. Ma to duże znaczenie dla sprawnego działania algorytmu przy niesymetrycznym i odkształconym napięciu sieci.

Jakość działania algorytmu PLL-DDSRF przedstawia rys. 12. W tym przypadku zasymulowana sieć pełna jest odkształceń harmonicznych. $\mathrm{THD}_{\mathrm{U}}=38 \%$, do tego jedna $\mathrm{z}$ faz jest asymetryczna względem dwóch pozostałych. Jak widać na załączonym rysunku algorytm synchronizacji radzi sobie mimo tych niesprzyjających warunków. Dzięki temu można stwierdzić, że ta metoda powinna być dedykowana dla rozwiązań wymagających szybkiego i dokładnego wykrywania kąta $\theta$.

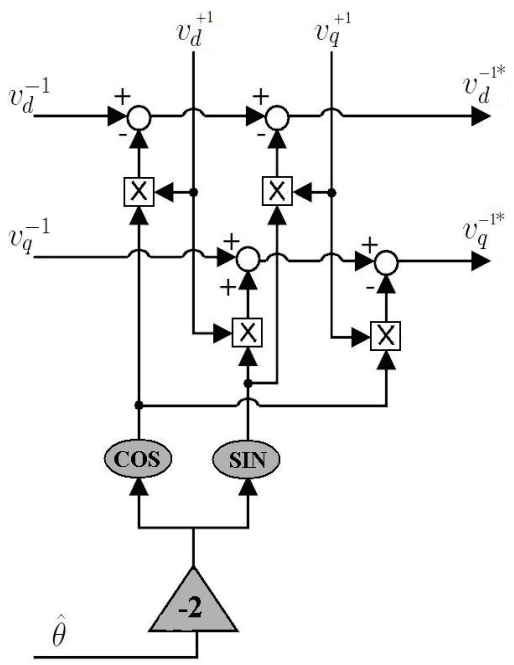

Rys. 11. Metoda oddzielenia oscylacji dla składowej pozytywnej

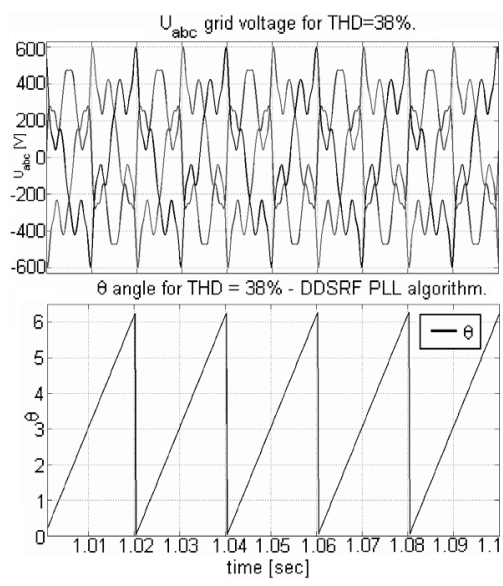

Rys. 12. Dzialanie PLL-DDSRF przy $T H D_{U}=38 \%$

\section{Podsumowanie}

Metody synchronizacji $\mathrm{z}$ siecią powinny być odpowiednio dobierane w zależności od wymagań dla danych rozwiązań. Algorytmy odporne na asymetrię napięć, harmoniczne są trudniejsze $\mathrm{w}$ implementacji, ale są w stanie sprostać stawianym im wymaganiom. W niniejszym artykule przedstawiono trzy metody synchronizacji z siecią, za pomocą pętli PLL. Wszystkie algorytmy zostały przetestowane za pomocą modeli symulacyjnych w środowisku MATLAB/Simulink.

Rozwój energoelektroniki, wraz z coraz częstszym stosowanie układów wymagających synchronizacji $\mathrm{z}$ siecią powoduje, że algorytmy służące do synchronizacji są stale rozwijane i ulepszane.

\section{Literatura}

[1] Akagi H., Kim H., The Instantaneous Power Theory on rotating p-q-r Reference Frames, IEEE International Conference on Power Electronics and Drive Systems, PEDS'99, July 1999, Hong Kong.

[2] Bergas J., Boroyevich D., Burgos R.P., Candela J.I., Pou J., Rodriguez P., Decoupled double synchronous reference frame PLL for power converters control, IEEE Trans. Power Electron., vol. 22, no. 2, pp. 584-592, Mar. 2007

[3] Blaabjerg, F. Ciobotaru M., Teodorescu R., A New Single-Phase PLL Structure Based on Second Order Generalized Integrator, Power Electronics Specialized Conference 2006, PESC'06, 37th IEEE 18-22 June 2006.

[4] Blaabjerg, F., Ciobotaru M. Teodorescu, R.; ed. (1996). A New Single-Phase PLL Structure Based on Second Order Generalized Integrator Power Electronics Specialists Conference, 2006. PESC'06. 37th IEEE 18-22 June 2006 Page(s): $1-6$

[5] Blaabjerg, F., Liserre, M., Timbus A., Teodorescu R.; Synchronization Methods for Three Phase Distributed Power Generation Systems. An Overview and Evaluation, Power Electronics Specialists Conference, 2005. PESC '05. IEEE 36th 16-16 June 2005.

[6] Guocheng S., Weiyang W., Xiaofeng S., Xiaoqiang G., Phase Locked Loop for electrically-interfaced converters in distributed utility networks, in Proceedings of International Conference on Electrical Machines and Systems (ICEMS 2008), Oct.17-20 2008, pp. 2346-2350.

[7] Levine W. S., ed. (1996). The Control Handbook. New York: CRC Press. ISBN 978-0-8493-8570-4.

[8] Instrukcja Ruchu i Eksploatacji Sieci Przesyłowej - IRiESP, PSE Operator, 1-10-2011.

[9] ENTSO-E Draft Network Code for Requirements for Grid Connection applicable to all Generators, European Network of Transmission System Operators for Electricity, 24 January $2012 \mathrm{http} / / / \mathrm{www}$.entsoe.eu.

\footnotetext{
Mgr inż. Piotr Lipnicki

e-mail: Piotr.Lipnicki86@gmail.com

Jest absolwentem Politechniki Lubelskiej i Uniwersytetu technicznego w Aalborgu. Zajmował się zagadnieniem kompensacji mocy biernej dla farm wiatrowych. Opracował metodę sterowania dla kompensatora mocy biernej STATCOM. Pracę magisterską pisał we współpracy $\mathrm{z}$ duńską firmą Vestas. Pracował nad zagadnieniem sterowania przekształtników napięciowych połączonych równolegle. Interesuje się zagadnieniem sieci inteligentnych „,smart grids”, w pracy doktorskiej zajmuje się algorytmami synchronizacji z przekształtników energoelektronicznych z siecią
}

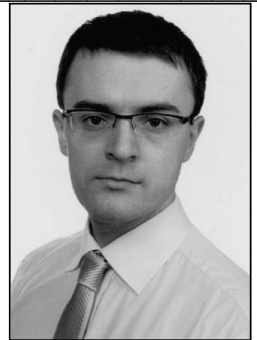

